\title{
Bird-Nest Fungus
}

by A. J. Hruska, Gerald

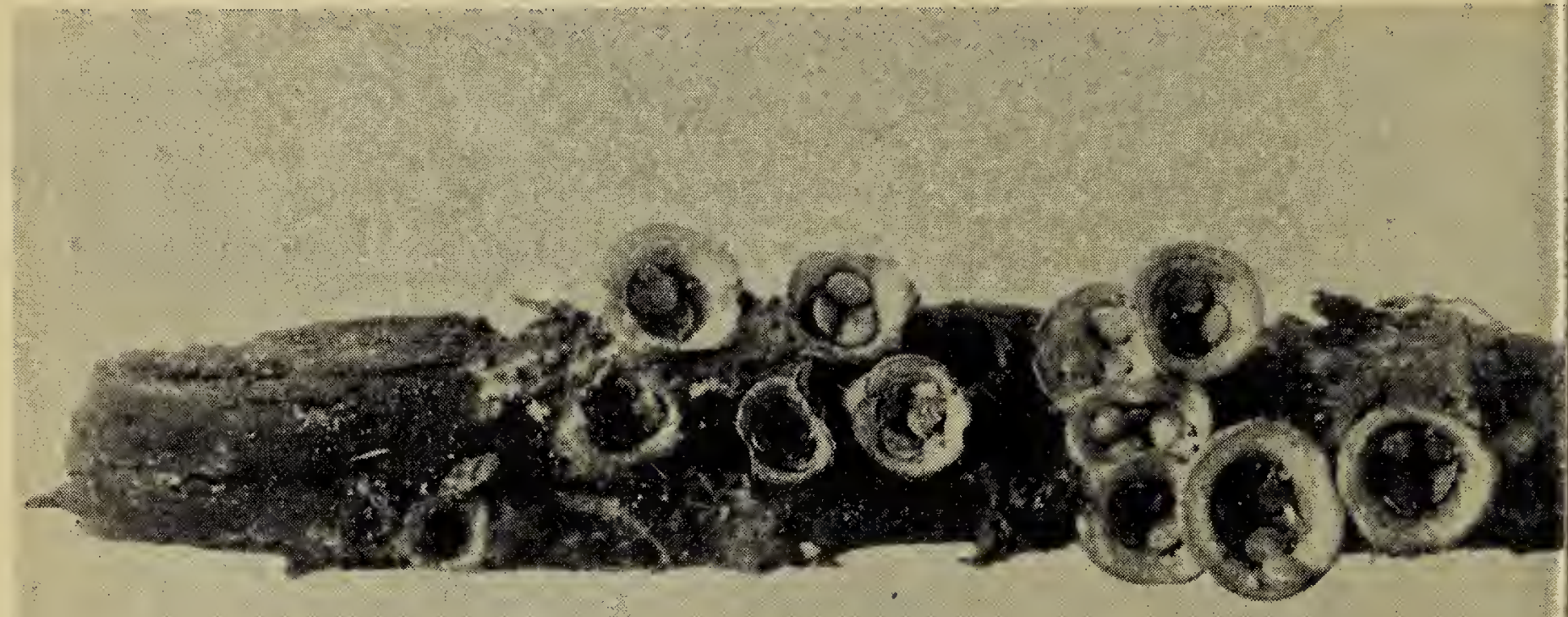

National Museum of Canada Photc Bird-nest Fungus showing peridiola in cups.

You will have to get down on your knees to see this small inconspicuous fungus. The Black Egg Bird-Nest Fungus Cyathus olla (Batsch) Pers. is one of the most astonishing creations to be found in the woods as far as its intricate method of reproduction is concerned.

The specimens in my collection are about $1 / 2$ inch high with the cups or openings about $1 / 4$ inch in width, attached to organic matter and forming close set colonies. Inside the cups are a number of black egg-like spore cases called peridiola fastened to the wall and bottom of these nests.

These "eggs" are smaller than

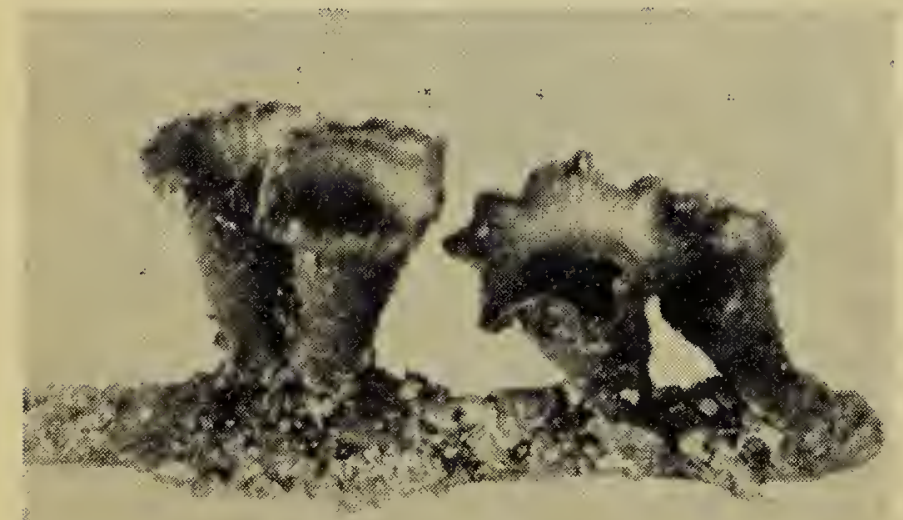

National Museum of Canada Photo General appearance of Bird-nest Fungus. mustard seed and contain thousand: of spores. For many years it has beer a riddle as to how the spores go out of the hard cases containing then and further how the cases got out o the little nest-like cups. Each per. idiolum is firmly attached with : strong fibrous cord to the wall of the cup.

As always in Nature, there is : reason. The cup is just right sized for a rain drop. During a rainstorm one pelting raindrop hitting the cur makes a splash and the peridiola ar knocked out. As the peridiola ar ejected the fibrous threads holding them follow like a comet's tail. A: they land the threads wrap them. selves around a twig, stem, etc., bol: fashion.

With the tiny bird-nest peridiol: hung up by threads on a stem, twig or leaf they become available to grazing or browsing animals. In ordes to grow and reproduce again the spores of this fungus must be eater by an animal, pass through the digestive system, and be voided, befort the spores will germinate and reproduce. The intricate process by which this fungus is reproduced has resulted in these small, choice treasures of Nature which are some. times called Splash Cups. 